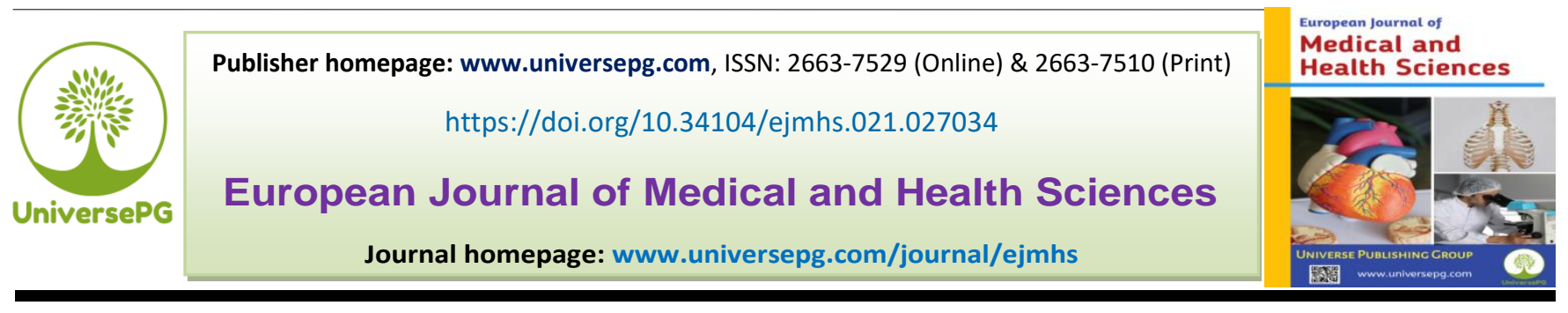

\title{
Assessment of Healthcare Practitioners' Insight into the Handover of Patients and its Implications for the Safety of Patients
}

\author{
Peter Waibode Alabrah ${ }^{1 *}$, Dennis Oju Allagoa ${ }^{1}$, and Anthony Okeoghene Eguvbe ${ }^{2}$ \\ ${ }^{1}$ Dept. of Obstetrics and Gynecology, Federal Medical Centre, Yenagoa, Nigeria; and ${ }^{2}$ Dept of Community Medicine, Federal \\ Medical Centre, Yenagoa, Nigeria. \\ *Correspondences: alabrahpee@gmail.com (Peter Waibode Alabrah, Dept. of Obstetrics and Gynecology, Federal Medical \\ Centre, Yenagoa, Nigeria).
}

\begin{abstract}
Inadequate and Indiscernible interpersonal communication between healthcare professionals or groups of professionals is a main causal factor in errors and procedural mistakes in medical practice, and this undermines the safety of patients. The study assessed healthcare providers' insight into the handover of patients and how this impacts on patient safety. A cross-sectional survey was utilized with a sample size of 400 , equally divided between nurses and doctors. A well-structured questionnaire was used to elicit the required information. The data collected were analyzed using SPSS 20.0 statistical package. The study revealed that the majority of the respondents had no formal training on patient handover $(56.3 \%$ vs. $43.7 \%)$. Respondents were aware that ineffective communication at handover impacts negatively patient safety. The traditional method of handover is practiced and the most employed type (77\%) and method (54\%) of communication is the combined written verbal method. The obstacles to effective communication at handover were time constraints, excess workload, fatigue, and distraction. It was concluded that the insight of healthcare providers about handover and its impact on patient handover is passable and it can be improved upon by including handover in the training curriculum of nursing/medical students, regular refresher courses for practicing nurses/doctors to equip them with the skills that will advance both the content and communication at handover.
\end{abstract}

Keywords: Handover, Safety, Healthcare practitioners, Patients, Patient care, Patient safety, and Communication.

\section{INTRODUCTION:}

Discontinuity of care given by medical personnel is an unavoidable reality of hospital care. This is because no care provider can work round-the-clock in a hospital setting as burn-out, stress, and somnolences will becloud the sense of perception, reasoning, and judgment. These eventually will compromise the safety of patients. Consequently, patients on admission will predictably be catered for by different care providers in the course of a day. Nurses' change shifts every 8 to 12 UniversePG I www.universepg.com hours, and, multiple physicians may be responsible for a patient's care at different times in the day. These breaks, breeds prospects for error when clinical information is not properly and accurately generated, processed and shared between healthcare providers. Handover is a critical aspect of "patient care that is neither well taught nor well practiced" (AMA, 2006). Though it has been recommended it is not included the academic curriculum of health professions (AMA, 2006). 
There is " 1 in a million chance of a person being harmed while travelling by plane. In comparison, there is 1 in 300 chance of a patient being harmed during healthcare" (WHO, 2018). "Estimates in developed countries revealed that as many as 1 in 10 patients is harmed while receiving hospital care" (WHO, 2018). Proficient and effective communication between healthcare providers at handover is pivotal to ensuring patient safety, and ultimately, averts medical errors that may result in mortality or maiming of a patient. Growing evidence has steered the World Health Organization to acknowledge communication in a handover in its top five patient safety solutions (WHO, 2007).

An estimated over 300 million handovers takes place each year in the United States of America (American Hospitals Association, 2014; CDCP, 2010) more than 40 million in Australia (Organization for Economic Co-Operation and Development, 2011) and over 100 million in England (Eggins and Slade, 2015), making handover perhaps the most regular and significant communicative course undertaken by medical personnel in the delivery of patient care (Health \& Social Care Information, 2012-2013), yet it is one of the least considered and taught rudiments of daily patient care. Miscommunication is a leading cause of preventable error in studies of closed malpractice claims (Kachalla et al., 2007; Singh et al., 2007; Shah et al., 2020).

Zinn, (1995) reported that of the 25000 to 30000 preventable adverse events that led to permanent disability in Australia, $11 \%$ were due to communication issues, in contrast to $6 \%$ due to inadequate skill levels of practitioners. Holly et al. (2004) and Reader et al. (2007) reported that ineffective intra-shift and inter-shift verbal and written communications were responsible for $57 \%$ and $37 \%$ of all the errors in healthcare respectively. Considering the crucial role played by patient handover in the continuum of care, the study aims to assess healthcare provider understanding of the process of patient handover and its implications for patient safety.

\section{METHODOLOGY:}

Research design - This prospective cross-sectional study was conducted at the Federal Medical Centre,
Yenagoa. The hospital has 425 bed capacities and is located at the Yenagoa metropolis, the capital city of Bayelsa State in the Southern Nigeria. It is a tertiary institution that provides all levels of health care services to patients, as well as training and research.

Sampling and data collection - The sample size was 400, made up of 200 doctors and 200 nurses. Cluster sampling was employed to equally administer closeended questionnaires to the respondents at the different wards/clinics. The objectives of the study were fully explained to the participants and their informed consent was obtained.

All recruited subjects were administered an anonymous well structured, close-ended questionnaire. They were requested to respond genuinely to the questions in the study instrument and they were guaranteed the confidentiality of the information provided. All grey areas were clarified without giving away the answer(s) or biasing any response(s).

All questionnaires were checked for completeness of response(s) on return. Participants were encouraged to provide answers to any question that was skipped and if they are uncompliant, their right to decline were respected.

Analysis - All data extracted and entered directly into SPSS version 20 which was used for the analysis of the data

Ethical approval - This was duly given by the ethical committee of the hospital

\section{RESULTS:}

$56.3 \%$ of medical personnel has had no formal training on handover of patients while 175(43.8\%) had formal training (Table 1).

Table 2 Examined which patients should be included in handovers, revealed that 369 (92.3\%) of the respondents agreed that all patients are to be handed over, $28(7.0 \%)$ indicated that only new and critically ill patients should be handed over, while $3(0.7 \%)$ respondents stated that only that only critically ill patients, should to be handed over 
Table 1: Sex distribution of respondents/if they have had any training on handover

\begin{tabular}{|c|c|c|c|c|c|c|}
\hline \multirow[t]{2}{*}{ Variables } & \multirow[t]{2}{*}{ Males } & \multirow[t]{2}{*}{ Females } & \multirow[t]{2}{*}{ Total (\%) } & \multicolumn{3}{|c|}{$\begin{array}{l}\text { Have you had any formal training on the } \\
\text { handover of patient }\end{array}$} \\
\hline & & & & Yes $(\%)$ & No (\%) & Total \\
\hline Doctors (\%) & $125(62.5 \%)$ & $75(37.5 \%)$ & $200(100 \%)$ & $175(43.8 \%)$ & $225(56.3 \%)$ & $400(100 \%)$ \\
\hline Nurses (\%) & $22(11 \%)$ & $178(89 \%)$ & $200(100 \%)$ & & & \\
\hline Total & $147(36.8 \%)$ & $253(63.2 \%)$ & 400 & & & \\
\hline
\end{tabular}

Table 2: Handover and its implications for patient safety

\begin{tabular}{|c|c|c|}
\hline VARIABLE & FREQ & \% \\
\hline Which patients should be included in handovers & 92.3 \\
\hline All patients & 369 & 7.0 \\
\hline New patients and those diagnosed as critically sick & 28 & 0.7 \\
\hline Only patients that are critically sick & 3 & 0.0 \\
\hline the only patient in whom an action is required & 0 & $100 \%$ \\
\hline TOTAL & 400 & \\
\hline
\end{tabular}

Table 3: Process and content of handover of patient

\begin{tabular}{|c|c|c|c|c|c|c|}
\hline \multirow{3}{*}{ Declaration } & \multicolumn{6}{|c|}{ Responses } \\
\hline & SA & $\mathbf{A}$ & D & SD & Decline & Total \\
\hline & Freq $(\%)$ & Freq $(\%)$ & Freq $(\%)$ & Freq $(\%)$ & Freq $(\%)$ & Freq $(\%)$ \\
\hline $\begin{array}{l}\text { Ineffective communication at handover is a } \\
\text { foremost cause of avoidable medical blunders. }\end{array}$ & $\begin{array}{c}224 \\
(56.0)\end{array}$ & $\begin{array}{c}161 \\
(40.3)\end{array}$ & $\begin{array}{c}10 \\
(2.5)\end{array}$ & $\begin{array}{c}5 \\
(1.2)\end{array}$ & & $\begin{array}{c}400 \\
(100)\end{array}$ \\
\hline $\begin{array}{c}\text { Transfer of information from an outgoing } \\
\text { shift/call to an incoming one is a fundamental } \\
\text { facet of handover. }\end{array}$ & $\begin{array}{c}272 \\
(68.0)\end{array}$ & $\begin{array}{c}101 \\
(25.2)\end{array}$ & $\begin{array}{c}13 \\
(3.3)\end{array}$ & $\begin{array}{c}2 \\
(0.5)\end{array}$ & & $\begin{array}{c}400 \\
(100)\end{array}$ \\
\hline $\begin{array}{l}\text { At handover report writing/taking notes is } \\
\text { essential, as it gives details of the health status } \\
\text { of each patients. }\end{array}$ & $\begin{array}{c}198 \\
(49.5)\end{array}$ & $\begin{array}{c}166 \\
(41.5)\end{array}$ & $\begin{array}{c}32 \\
(8.0)\end{array}$ & $\begin{array}{c}4 \\
(1.0)\end{array}$ & & $\begin{array}{c}400 \\
(100)\end{array}$ \\
\hline $\begin{array}{l}\text { Verbal handover method is best apt for the } \\
\text { sharing of pertinent facts about patients } \\
\text { care/general ward issues }\end{array}$ & $\begin{array}{c}131 \\
(32.8)\end{array}$ & $\begin{array}{c}176 \\
(44.0)\end{array}$ & $\begin{array}{c}81 \\
(20.2)\end{array}$ & $\begin{array}{c}12 \\
(3.0)\end{array}$ & & $\begin{array}{c}400 \\
(100)\end{array}$ \\
\hline $\begin{array}{l}\text { Report writing gives details about the health } \\
\text { condition of patients and when combined with } \\
\text { written verbal method is the best form of } \\
\text { handover }\end{array}$ & $\begin{array}{c}234 \\
(58.5)\end{array}$ & $\begin{array}{c}130 \\
(32.5)\end{array}$ & $\begin{array}{c}33 \\
(8.3)\end{array}$ & $\begin{array}{c}3 \\
(0.7)\end{array}$ & & $\begin{array}{c}400 \\
(100)\end{array}$ \\
\hline
\end{tabular}

\section{Strongly agree (SA), Agree (A), strongly disagree} (SD), Disagree (D)

As shown in Table 3, the process and content of handing over of patient revealed that $224(56.0 \%)$ respondents strongly agreed that ineffective communication at handover is a leading cause of preventable medical errors; 161 (40.3\%) respondents agree; $10(2.5 \%)$ other respondents disagree while the remaining $5(1.2 \%)$ respondents strongly disagreed. 272 UniversePG I www.universepg.com
$(68.0 \%)$ of respondents strongly agreed that the transfer of information from an outgoing shift/call to an incoming one is a critical aspect of handover; 101 (25.2\%) other respondents agree; 13 (3.3\%) respondents disagree while the remaining $2(0.5 \%)$ respondents strongly disagree. 198 (49.5\%) of the respondents strongly agree that report writing gives details of the health status of each patient in the handover process; another $166(41.5 \%)$ respondents agree; 32 
$(8.0 \%)$ of the respondents disagree while the remaining $4(1.0 \%)$ other respondents strongly disagree. 131 (32.8\%) of respondents strongly agree that verbal handover is best suited for the exchange of relevant information about patients care/general ward issues; $176(44.0 \%)$ of respondents agree; $81(20.2 \%)$ other respondents disagree while the remaining $12(3.0 \%)$ respondents strongly disagree. Report writing gives specifics about the health condition of patients in the handover process and when combined with written verbal method is the best form of handover was strongly agreed to by $234(58.5 \%)$ respondents; 130 $(32.5 \%)$ of respondents agree; $33(8.3 \%)$ respondents disagree while the remaining $3(0.7 \%)$ respondents strongly disagree.

Table 4: Implications of handover on patient care and safety

\begin{tabular}{|c|c|c|c|c|c|c|}
\hline \multirow{3}{*}{ Declaration } & \multicolumn{6}{|c|}{ Responses } \\
\hline & $\mathbf{S A}$ & $\mathbf{A}$ & D & SD & Declined & Total \\
\hline & Freq $(\%)$ & Freq $(\%)$ & Freq $(\%)$ & Freq $(\%)$ & Freq $(\%)$ & Freq $(\%)$ \\
\hline $\begin{array}{l}\text { An essential element of patient handover is } \\
\text { prioritizing giving of care. }\end{array}$ & $160(40.0)$ & $\begin{array}{c}190 \\
(48.0)\end{array}$ & $23(5.8)$ & $9(2.2)$ & $23(5.8)$ & $400(100)$ \\
\hline $\begin{array}{l}\text { Lateness to work causes hurrying over the } \\
\text { handover process and this will lead to } \\
\text { ineffective communication. }\end{array}$ & $211(52.8)$ & $\begin{array}{c}158 \\
(39.5)\end{array}$ & $22(5.5)$ & $9(2.2)$ & --- & $\begin{array}{c}400 \\
(100)\end{array}$ \\
\hline $\begin{array}{c}\text { There should be a well-defined delineation of } \\
\text { who is responsible for ensuring important tasks } \\
\text { are coordinated and accomplished for each } \\
\text { patient or group of patients. }\end{array}$ & $122(30.5)$ & $206(51.5)$ & $54(13.5)$ & $2(0.5)$ & $16(4.0)$ & $\begin{array}{c}400 \\
(100)\end{array}$ \\
\hline $\begin{array}{l}\text { An improvement in patient safety and staff } \\
\text { familiarity with a patient will ensue with a } \\
\text { written handover document. }\end{array}$ & $\begin{array}{c}113 \\
(28.2)\end{array}$ & $164(41.0)$ & $23(5.8)$ & $4(1.0)$ & $96(24.0)$ & $\begin{array}{c}400 \\
(100)\end{array}$ \\
\hline
\end{tabular}

Solutions in Table 4 represent the implications of handover on patient care and refuge. It revealed that $160(40.0 \%)$ of the respondents strongly agreed that the crucial factor in patient handover is the prioritization of care; $190(48.0 \%)$ other respondents agree; 23(5.8\%) another respondent disagree while the remaining $9(2.2 \%)$ respondents strong disagreed. On whether lateness to work causes hurrying over the handover process and which may lead to ineffective communication, $211(52.8 \%)$ of respondents strongly agree; $158(39.5 \%)$ other respondents agree; $22(5.5 \%)$ respondents disagree while the remaining 9(2.2\%) respondents strongly disagree. $122(30.5 \%)$ of respondents strongly agree that there should be a distinct delineation of who is responsible for ensuring important tasks are coordinated and accomplished for each patient or group of patients; another 206(51.5\%) respondents agree; $54(13.5 \%)$ of the respondents disagree while the remaining $2(0.5 \%)$ respondents strongly disagree. 16(4.0\%) declined answering. Correspondingly, $113(28.2 \%)$ and $164(41.0 \%)$ of respondents strongly agree and agree respectively that an improvement in patient safety and staff familiarity with patients will occur if a written handover document were to be produced; $23(5.8 \%)$ other respondents disagree while another $4(1 \%)$ of the respondents strongly disagree. 96(24.0\%) declined answering.

Table 5: Implications of handover on patient care and safety

\begin{tabular}{|c|c|c|c|c|c|c|}
\hline \multirow[b]{2}{*}{ Declaration } & \multicolumn{6}{|c|}{ Responses } \\
\hline & Never $(\%)$ & Rarely (\%) & Most of the time (\%) & Always (\%) & Declined & Total $(\%)$ \\
\hline $\begin{array}{l}\text { Handover information is routinely } \\
\text { perused and updated regularly by } \\
\text { you during the shift or call. }\end{array}$ & $16(4.0)$ & $95(23.8)$ & $148(37.0)$ & $141(35.3)$ & & $\begin{array}{c}400 \\
(100)\end{array}$ \\
\hline
\end{tabular}




\begin{tabular}{|c|c|c|c|c|c|c|}
\hline $\begin{array}{c}\text { A frequent mode of handover is } \\
\text { verbal communication. How often } \\
\text { can you recollect information } \\
\text { relayed on to you? }\end{array}$ & $2(0.5)$ & $61(15.3)$ & $261(65.3)$ & $76(19.0)$ & $\begin{array}{c}400 \\
(100)\end{array}$ \\
\hline $\begin{array}{c}\text { Handovers kick starts work } \\
\text { schedules, are there specific gadgets } \\
\text { (electronic or otherwise) in place } \\
\text { that hints at accomplishment of } \\
\text { certain task. }\end{array}$ & $18(45.8)$ & $111(27.7)$ & $67(16.7)$ & $28(7.0)$ & $11(2.8)$ & 400 \\
\end{tabular}

Results in Table 5 which represent the implications of handover on patient care and safety shows that $141(35.3 \%)$ respondents always routinely crossed checked and updated regularly handover information in the course of the shift or call; 148(35.3\%) of the respondents does so most of the time; 95(23.8) respondentsdo so rarely while $16(4.0 \%)$ of respondents never cross check nor update handover information. On "a frequent mode of handover is verbal communication, how often can you recall information passed-on, to you"? 261(65.3\%) respondents stated most of the time, 76(19.0\%) respondents stated it is always, for 61 $(15.3 \%)$ of respondents it was rarely while the remaining $2(0.5 \%)$ of respondent stated that they never recall information passed. On handovers kick starts work schedules, are there specific gadgets (electronic or otherwise) in place that hints at accomplishment of certain task? 183(45.8\%) respondents stated never; $111(27.7 \%)$ of respondents stated it was occasional; $67(16.7 \%)$ of the respondents stated it was most of the time while the remaining $28(7.0 \%)$ respondents stated it was always. 11(2.8\%) declined.

On communication type employed at handover, majority of the respondents $319(79.8 \%)$ used the combine written and verbal method; $64(16.0 \%)$ of respondents used the verbal method; $5(1.2 \%)$ respondents used taped while $2(0.5 \%)$ respondent each for written only and written verbal methods (Table 6).

Table 6: Communication type employed at handover

\begin{tabular}{|c|c|c|c|c|c|c|c|}
\hline $\mathbf{V}$ & $\begin{array}{c}\text { Verbal } \\
(\%)\end{array}$ & $\begin{array}{c}\text { Written } \\
\text { only }(\%)\end{array}$ & $\begin{array}{c}\text { Written } \\
\text { verbal }(\%)\end{array}$ & \begin{tabular}{|c|} 
Non- \\
Verbal $(\%)$
\end{tabular} & $\begin{array}{c}\text { Combine written } \\
\& \text { verbal }(\%)\end{array}$ & $\begin{array}{c}\text { Taped } \\
(\%)\end{array}$ & \begin{tabular}{|c|} 
Total \\
$(\%)$
\end{tabular} \\
\hline $\begin{array}{c}\text { Type of communication practiced } \\
\text { during handover }\end{array}$ & $\begin{array}{c}64 \\
(16.0)\end{array}$ & $\begin{array}{c}2 \\
(0.5)\end{array}$ & $\begin{array}{c}2 \\
(0.5)\end{array}$ & $\begin{array}{c}8 \\
(2.0)\end{array}$ & $\begin{array}{c}319 \\
(79.8)\end{array}$ & $\begin{array}{c}5 \\
(1.2)\end{array}$ & $\begin{array}{c}400 \\
(100)\end{array}$ \\
\hline $\begin{array}{l}\text { What communication type is most } \\
\text { often employed in patient handover }\end{array}$ & $\begin{array}{c}167 \\
(41.7)\end{array}$ & $\begin{array}{c}9 \\
(2.3)\end{array}$ & $\begin{array}{c}0 \\
(0.0)\end{array}$ & $\begin{array}{c}5 \\
(1.2)\end{array}$ & $\begin{array}{c}216 \\
(54.0)\end{array}$ & $\begin{array}{c}3 \\
(0.7)\end{array}$ & $\begin{array}{c}400 \\
(100)\end{array}$ \\
\hline
\end{tabular}

Table 7: Type of handover and barriers to communication at handover

\begin{tabular}{|c|c|c|c|c|}
\hline Variable & Yes (\%) & No (\%) & Declined (\%) & Total (\%) \\
\hline $\begin{array}{c}\text { Do you have a written well laid-out, handover } \\
\text { document/'patient list' in some/all of the wards }\end{array}$ & $96(24.0)$ & $304(76.0)$ & $\cdots---$ & $400(100)$ \\
\hline Lack of time & $255(63.7)$ & $51(12.8)$ & $94(23.5)$ & $400(100)$ \\
\hline Fatigue & $285(71.3)$ & $37(9.3)$ & $78(19.5)$ & $400(100)$ \\
\hline Distraction & $235(58.8)$ & $40(13.5)$ & $111(27.8)$ & $400(100)$ \\
\hline Excess workload & $335(83.8)$ & $17(4.3)$ & $48(12)$ & $400(100)$ \\
\hline
\end{tabular}

Table 7 shows that $304(76.0 \%)$ respondents stated that there is no written well laid-out, handover document/'patient list' in some/all of the wards, while 96 (24\%) respondents stated yes. On the barriers to com- munication at handover; Lack of time $255(63.7 \%)$ of respondents said yes while 51(12.8\%) respondents said no and the other 94(23.5\%) respondents declined. On fatigue $285(71.3 \%)$ of respondents said yes while 
$37(9.2 \%)$ respondents said no and the other $78(19.5 \%)$ respondents declined. On distraction $235(58.8 \%)$ of respondents said yes while $40(13.4 \%)$ said no and $111(27.8 \%)$ declined answering. On excess workload $335(83.8 \%)$ of respondents said yes while $17(4.3 \%)$ respondents said no and the remaining 48(12.0\%) respondents did not answer.

\section{DISCUSSION:}

The study revealed that $56.3 \%$ of respondents had not had any formal training on patient handover; this infers that majority of the nurses and doctors that routinely handover patients had no formal coaching. This mirrors the finding by other authors (AMA, 2006; Eggins and Slade, 2015; Bomba and Prakash, 2005; Arora et al., 2009). This is not surprising because it is not part of the academic curriculum in the training institutions and health institutions do not routinely undertake training of medical personnel on handover prior to assumption of duty (Saha et al., 2020).

Majority of the respondents rightly stated that, all patients on admission is to be handed over. However, $7 \%$ of respondents erroneously stated that new admissions and those diagnosed as critically ill are the patients to be handed over while $0.7 \%$ of the respondents opined that only the critically ill patients are to be handed over. This mirrors the fact that majority of respondents, had no formal training on handover of patients however, irrespective of how small these percentages are, the lack of the knowledge that all patients should be handed over, invariably put the patients in harm's way. The predominant type of handover is the traditional method of handover, $76.0 \%$ of the respondents rightly stated that they do not you have a written well laid-out, handover document/ 'patient list' in some/all of the wards as it obtains in the standardized method of handover. This invariably impacts on the communication method employed during handover of patients. The study revealed that the predominant communication type and method used at handover is the combine written and verbal method. This method has been reported as the most effective means of communication at handover as it combines the advantages of both methods and recall is best achieved (Bomba and Prakash, 2005; Arora et al., 2009). The barriers to communication at handover were lack of time, fatigue,

UniversePG I www.universepg.com distraction and excess workload. This corroborates the findings by other authors (Bhabra et al., 2007; Kessler et al., 2014).

The study revealed that handover has great implycation on patient care and safety. As highlighted rightly by majority of respondents, crucial factors in patient handover are; the prioritization of care, lateness to work causes rushing of the handover process and this will lead to ineffective communication, establishing a distinct delineation of which staff is responsible for ensuring important tasks are coordinated and accomplished for each patient or groups of patient and an improvement in patient safety will ensue and staff familiarity with patients will occur if a written handover document were to be produced. However, it is worrisome when the percentage disagreeing with the above is considered. For example $14 \%$ of respondents disagree that there should be a distinct delineation of who is responsible for ensuring important tasks are coordinated and accomplished for each patient or group of patients. As reported by Greenberg et al. (2007) failure to institute this at the start of shift/call duty, evidently puts the patient at risk as there will be no-appropriate delineation and assignment of duties and responsibilities at the commencement of the shift/call to ensure that all tasks and care are conscientiously undertaken. Similarly $7.7 \%$ of respondents disagrees that lateness to work causes hurrying over the handover process and this will lead to ineffective communication. The scenario is such that one staff is late and needs to take over to start his/her duties while the other is exhausted and amongst other considerations, need to get home as soon as possible. This is a ready atmosphere for ineffective communication as some of the necessary information needed to be passed on, may be skipped or glossed over. This invariably compromises the safety of the patients under this team. These underscore the importance of a formal training and retraining on handover.

Thepredominant communication type and method used at handover is the combine written and verbal method respectively. Bhabra et al. (2007) reported that regularly updating the written or printed sheets in the course of handover ensure that the information passed at handover is retained. Majority of the respondents stated that handover information is routinely cross 
checked and updated regularly by them in the course of the shift or call as judge by the respondents that do so "most of the time or always" (Table 5). The percentage of respondents that update the written document "occasionally" and "never" account for $23.8 \%$ and $4.0 \%$ respectively. This is unacceptably high considering that patient care and safety will be compromised by these sets of respondents as they are likely to lose tract of updated critical aspects of management of the patients. After the combine written and verbal method of communication, the next frequent mode of communication is the verbal method and respondents stated that most of the time they can recall the information passed while $15.3 \%$ of respondents stated they do so occasionally. Verbal handovers contained more information than written handovers however, Bhabra et al., (2007) reported that when patient information is handed over by the verbal only method, very few facts are retained, accordingly the authors advised that this method should be avoided whenever possible.

Review of the process and content of handover of patient revealed that respondents were well aware that ineffective communication at handover is a leading cause of preventable medical errors. They were also aware that the transfer of information from an outgoing shift/call to an incoming one is a critical aspect of handover and that writing of report gives specific details of the health condition of each patient in the handover process. These are keys elements of patient safety that the handover process is supposed to be diligently and painstaking undertaken at the conduct of each handover of patient. It is established that when compared to the verbal method it remarkably reduces the time spent at handover as there is no interruption, however it is not recommended. It is the least mode of handover communication employed in the institution.

\section{Limitation of the study}

Considering the sampling technique employed, if the health care practitioners sampled, are bias in their responses, then this will infer that the other practitioners have the same erroneous opinion.

\section{CONCLUSION:}

The assessment of healthcare providers' comprehension of handover and its relation to patient safety is reasonably good, when it is related to the fact that majority of the respondents have not been formally trained.We therefore recommend the incorporation of handover in the training curriculum of nursing/medical students, those already employed should at least twice yearly undergo regular updates on the knowledge and practice of handover to improve handover content and communication. All newly employed nurses/doctors should undergo compulsory training on patient handover before assumption of duty.

\section{ACKNOWLEDGEMENT:}

Authors appreciate Dr. Doni Doni Paul for his assistance and Miss Happiness Ndunuwe for typing this manuscript.

\section{CONFLICTS OF INTEREST:}

The authors declare no conflict of interest.

\section{REFERENCES:}

1. American Hospitals Association, Fast Facts, (2014). Available online from: http://www.aha.org/research/rc/stat-studies/fastfacts.shtml

2. Arora, V. M., Dressler, and Kripalani, S. (2009). Hospitalist handoffs: a systematic review and task force recommendations. J Hosp Med., 433-440. https://doi.org/10.1002/jhm.573

3. Australian Medical Association, (AMA), (2006). Safe handover: safe patients. AMA Clinical Handover Guide, Sydney. Available from: http://ama.com.au/node

4. Bhabra, G., Mackeith, S., Monteiro, P., \& Pothier, D. D. (2007). An experimental comparison of handover methods. Ann R Coll Surg Engl, 89, 298-300.

https://doi.org/10.1308/003588407X168352

5. Bomba, D. T. \& Prakash, R. (2005). A description of handover processes in an Australian public hospital. Aust Health Rev., 29: 68-79. https://doi.org/10.1071/ah050068

6. Centres for Disease Control and Prevention, (CDCP), (2010). National Hospitals Discharge Survey. (2010). Table, number, and rate of hospitals discharges. Available from:

http://www.cdc.gov/nchs/data/nhds/1general/201 Ogen1_agesexalos.pdf 
7. Eggins, S. and Slade, D. (2015). Communication in clinical handover: improving the safety and quality of the patient experience. $J$ Public Health Res., 4(3): 666.

https://doi.org/10.4081/jphr.2015.666

8. Greenberg, C.C., Regenbogen, S.E., and Gawande, A.A. (2007). Patterns of communication breakdowns resulting in injury to surgical patients. J Am Coll Surg., 204: 533-540.

http://www.atulgawande.com/documents/2007J ACS--CommunicationBreakdowns.pdf

9. Health \& Social Care Information. (20122013). Hospital Episode Statistics, Admitted Patient Care. http://www.hscic.gov.uk

10. Holly C, and Poletick, E. B. (2014). A systematic review on the transfer of information during nurse transitions in care. J Clin Nurs, 23:2387-395.https://doi.org/10.1111/jocn.12365

11. Johnson M, Kelly B, et al. (2014). Comparing nursing handover and documentation: Forming one set of patient information. IntNurs Rev., 61: 73-81. https://doi.org/10.1111/inr.12072

12. Kachalia, A., Puopolo, and Studdert, D.M. (2007). Missed and delayed diagnoses in the emergency department: a study of closed malpractice claims from 4 liability insurers. Ann Emerg Med., 49, pp.196-205.

13. Kessler C, Jordan J, Beach C, and Coletti MC. (2014). Interunit Handoffs of patients and transfers of information: A survey of current practices; Ann Emerg Med., 64, 343-349.

http://dx.doi.org/10.1016/j.annemergmed.2014.0 4.022

14. Organization for Economic Co-Operation and Development, (OECD). (2011). Health care utilization: hospital aggregates. Available from: http://stats.oecd.org/index.aspx

15. Patient safety network, (2017). Handoffs and Signout. Retrieved 12 $2^{\text {th }}$ December 2018 from https://psnet.ahrq.gov/primer
16. Reader, T.W., Flin, R. and Cuthbertson, B.H. (2007). Communication skills and error in the intensive care unit. CurrOpinCrit Care., 13(6): 732-736. https://doi.org/10.1097/MCC.0b013e3282f1bb0e

17. Saha S, Saha JV, and Afroz D. (2020). Prescribing pattern of medical practitioners in their private chamber practice according to $\mathrm{WHO}$ prescribing indicators in a southern district of Bangladesh. Eur. J. Med. Health Sci., 2(2), 1620. https://doi.org/10.34104/ejmhs.020.16020

18. Shah S, Rana S, and Jalali MA. (2020). Study on awareness, knowledge and practice of breast screening methods among the female students of BUHS, Eur. J. Med. Health Sci., 2(6), 152-158.

https://doi.org/10.34104/ejmhs.020.01520158

19. Sifat Uz Zaman M, Afrin S, and Biswas SM. (2021). Awareness, attitude and practice on sterilization among healthcare staffs of a tertiary hospital in Bangladesh, Eur. J. Med. Health Sci., 3(1), 12-18.

https://doi.org/10.34104/ejmhs.021.012018

20. Singh, H., Thomas, E.J., and Studdert, D.M. (2007). Medical errors involving trainees. Arch Intern Med., 67: 2030-2036. https://doi.org/10.1001/archinte.167.19.2030

21. World Health Organization, (WHO). 10 Facts on patient safety (Updated March 2018). http://www.who.int/features/factfiles/patient_saf ety/en/

22. World Health Organization, (WHO), (2007). Communication during patient handovers, Patient Safety Solutions, 1(3). Accessed from https://www.who.int/news-room/facts-in-picture s/detail/patient-safety

23. Zinn C. (1995). 14,000 preventable deaths in Australia. BMJ, 310, 1487.

https://doi.org/10.1136/bmj.310.6993.1487

Citation: Alabrah PW, Allagoa DO, and Eguvbe AO. (2021). Assessment of healthcare practitioners' insight into the handover of patients and its implications for the safety of patients, Eur. J. Med. Health Sci., 3(2), 27-34. https://doi.org/10.34104/ejmhs.021.027034 () 